Epidemiology

\section{Assessing historical exposure is like solving a mystery}

\section{H Kromhout}

\section{Commentary on the paper by Johansen et al (see page 434)}

$\mathrm{H}$ istorical exposure assessment for epidemiological studies has always been a great challenge for occupational hygienists and exposure assessors. In the paper by Johansen and colleagues ${ }^{1}$ published in this issue of the journal, the authors describe what they call "history science methods" for exposure assessment for occupational health studies. The paper reads likes a detective story, with this exception that not only the culprits (exposed) have to be identified but also the innocents (non-exposed). Their approach is unconventional, given that they start from very unlikely sources for exposure assessment such as census data, telephone books, and biographies. The census was even the sampling frame, because identifying a cohort of small shop owners and employees through regular means (approaching companies, employer's organisations, pension funds) was impossible. Instead the authors started with the computerised 1970 Danish census data. Of course these files contained a personal identification number (so typical for the Scandinavian countries and almost nonexistent in most other countries) with which data linkage became an option. Unfortunately (or luckily) the researchers had to go beyond the electronic files, because the available job codes in the files were not detailed enough to separate dry cleaners from laundry workers and dyers. The personal identification number enabled linkage to the Danish Cancer Register and so case-control studies nested within a general population sample could be consequently designed.

After cases and controls were identified, it was however still unclear who was exposed and who was not (the plot still had to be solved). The researchers were lucky to learn that in the dungeons of the Danish National Archives the actual filled-in census forms containing free text on employment were still available. This enabled the researchers to partly assess the exposure status of cases and controls by separating dry cleaners from laundry workers.
For the dry cleaners, intensity and duration of exposure was estimated through length of employment and number of people employed at their workplaces. This information was partly obtained from pension funds (employees) and a biographical registration of self-employed dry cleaning and laundry workers unearthed in the Royal Library. The length of employment for selfemployed not present in the biography, was estimated from the number of years their name was listed as an owner in the telephone books (also available in the Royal Library of Denmark). The occupational codes together with size of the company were used to distinguish between (a) dry cleaners and other workers in small shops (less than 10 employees), (b) other workers in dry cleaning shops with more than 10 individuals, and (c) unexposed laundry workers.

The decision to combine dry cleaners with workers from small shops with other jobs was a very sensible one, since, as was noted in the IARC monograph on dry cleaning, "differences in personal exposure to tetrachloroethylene between dry cleaning plants and shops are often many times larger than the differences between machine operators and other staff within dry cleaning

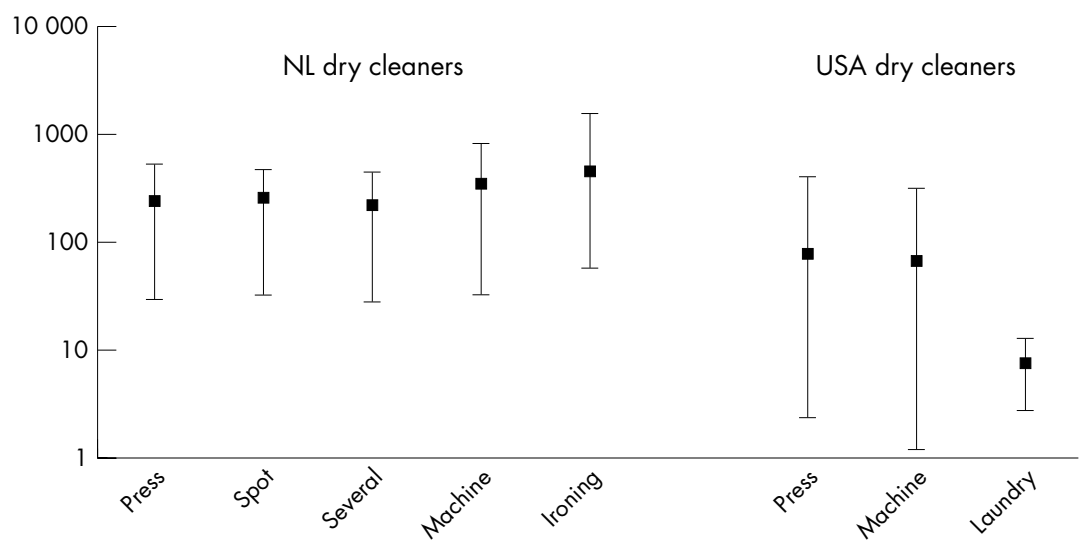

Figure 1 Range and average (AM) exposure of dry cleaners in the Netherlands and in the USA by job (NL: 5 job codes, 23 workers, 113 measurements; USA: 3 job codes, 13 workers, 58 measurements). premises". ${ }^{2}$ This was based on statistical analyses of measurement data from three dry cleaning shops in the Netherlands $^{3-5}$ and 12 dry cleaning shops in the USA $^{6}$ for which repeated personal measurement data was available in the WAUNC database. ${ }^{7}$ In figs 1 and 2 the measurement results of these 12 shops are broken down by, respectively, job and shop. What is obvious from the graphs was confirmed in the analyses of variance that hardly showed between-job variability in average exposure within a shop, but a large difference in average exposure between shops. This led to the conclusion that applying fixed multipliers for job titles in the calculation of cumulative exposure to tetrachloroethylene will introduce severe misclassification in this industry when factors that modify exposures in specific plants and shops are not taken into account. ${ }^{2}$

Johansen et al moved from the Royal Archives to the archives of the Labour Inspection Agency, the Danish Medical Association, and the National Institute of Occupational Health for reports on poisoning cases and measurements of tetrachloroethylene. The returns of this exercise were relatively meagre given that most of the measurements were short term measurements and not stemming from representative sampling strategies or the period of interest (196476). Measurements made by the Danish Technological Institute in 1979-80 appeared to be most valuable, and additional measurement results were obtained from a Scandinavian database.

This inconceivable wealth of information obtained by the authors was consequently used to sketch a very detailed picture of the state of affairs in dry cleaning in Denmark around 1970 (using the information obtained for the controls). The numbers of workers in dry cleaning shops, the number of dry 


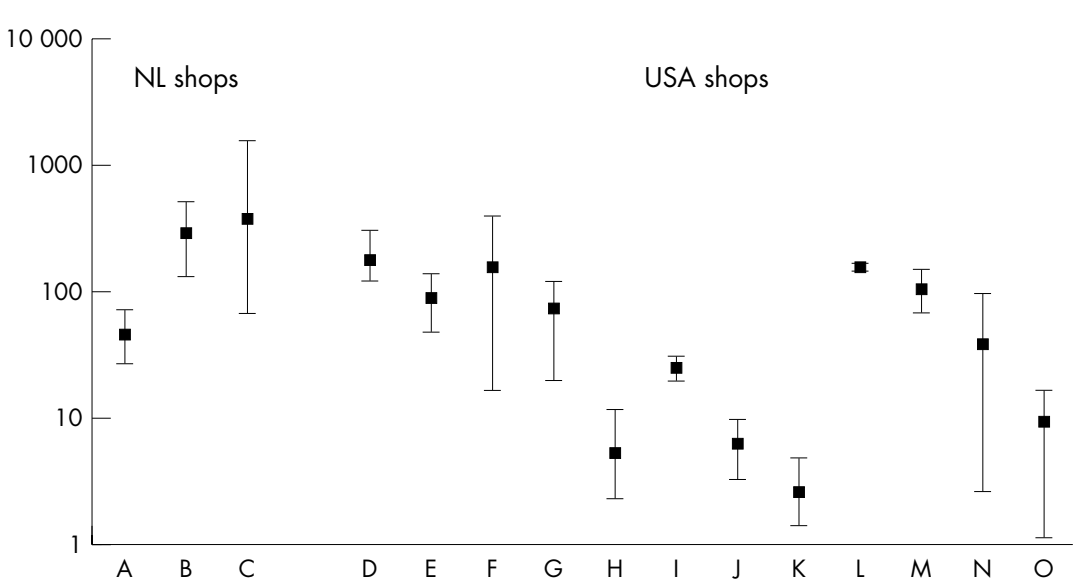

Figure 2 Range and average (AM) exposure of dry cleaners in the Netherlands and in the USA by dry cleaning shop (NL: 3 shops, 23 workers, 113 measurements; USA: 12 shops, 13 workers, 58 measurements).

cleaners, the average number of dry cleaning machines per shop, the number of tons of tetrachloroethylene used by these shops, and the average exposure in a shop are just part of this very detailed picture. The authors were able to validate some of their estimates satisfactorily through additional sources of information. They also convincingly claim that the exposure in dry cleaning shops Denmark was considerably lower than in the USA in this time period.

The critique on the lack of valid exposure data in studies addressing the carcinogenicity of tetrachloroethylene ${ }^{8}$ will be irrelevant for the Danish casecontrol study. One might only hope that the authors' decision to assume the exposure level to be constant from 1964 to 1979 was only part of the exposure assessment strategy for the case-control study, since differences between shops such as lay-out, ventilation, and dimensions of the shop, to name a few, will have resulted in shops with distinctly different exposure levels (see fig 2).

Contrary to what the authors claim, I think that we in occupational health epidemiology do usually search for literature outside the "Medline world". Unfortunately the wealth of data available to the authors in Denmark is something exposure assessors in other countries can only dream of. Nevertheless, the authors have set the standard for the use of history science in exposure assessment that others should strive for. Ironically this paper comes from the same country where recently the national occupational hygiene society ceased to exist. More disadvantaged exposure assessors (such as, for instance, from my country, where the

\section{Silica: déjà vu all over again?}

\section{K Steenland}

\section{Commentary on the paper by Brown and Rushton (see page 446)}

B rown and Rushton ${ }^{1}$ have conducted a retrospective cohort mortality study of 2700 workers in the industrial sand industry. Work in the industrial sand industry results in exposure to crystalline silica, and the focus of the study was whether exposure to silica causes lung cancer. Retrospective exposure assessment, based on air measurements since 1978, and some assumptions about exposure before then, was used to estimate exposure
Ministry of Social Affairs and Employment does not even keep copies of their yearly updated Occupational Exposure Limits lists) might consider a move to Denmark.

Occup Environ Med 2005;62:429-430.

doi: 10.1136/oem.2004.019158

Correspondence to: $\mathrm{Dr} \mathrm{H}$ Kromhout, Environmental and Occupational Health Division, Institute for Risk Assessment Sciences, Utrecht University, PO Box 80176, 3508 TD

Utrecht, Netherlands; H.Kromhout@iras.uu.nl

Competing interests: none declared

\section{REFERENCES}

1 Johansen $\mathrm{K}$, Tinnerberg $\mathrm{H}$, Lynge E. Use of history science methods in exposure assessment for occupational health studies. Occup Environ Med 2005;62:434-41.

2 International Agency for Research on Cancer (IARC). Dry cleaning, some chlorinated solvents and other industrial chemicals, Vol 63. Lyon: IARC, 1995.

3 van der Tuin J, Hoevers W. Perchloroethylene in dry cleaning services (TNO Report F1560). Rijswijk, TNO, 1977a (in Dutch).

4 van der Tuin J, Hoevers W. Perchloroethylene in dry cleaning services (TNO Report F1590). Rijswijk, TNO, $1977 b$ (in Dutch).

5 van der Tuin J, Hoevers W. Perchloroethylene in dry cleaning services (TNO Report F1560). Rijswijk, TNO, 1979 (in Dutch).

6 Petreas MX, Rappaport SM, Materna BL, et al. Mixed exhaled air measurements to assess exposure to tetrachloroethylene in dry cleaners. $J$ Exp Anal Environ Epidemiol 1992; (suppl 1):25-39.

7 Kromhout H, Symanski E, Rappaport SM. A comprehensive evaluation of within-and betweenworker components of occupational exposure to chemical agents. Ann Occup Hyg 1993;37:253-70.

8 Mundt KA, Birk T, Burch MT. Critical review of the epidemiological literature on occupational exposure to perchloroethylene and cancer. Int Arch Occup Environ Health 2003;76:473-91.

9 Burstyn I, Kromhout H, Cruise PJ, et al. Designing an international industrial hygiene database of exposures among workers in the asphalt industry. Ann Occup Hyg 2000;44:57-66.

did they find any excess silicosis (only two silicosis deaths were observed). Furthermore, they did not find a positive exposure-response trend for lung cancer by cumulative exposure category (rate ratios of 1.0, 1.24, 1.42, and 0.88 by increasing exposure).

Should this negative result be considered surprising? After all, the International Agency for Research on Cancer (IARC) declared in 1997 that crystalline silica was a group I (definite) human carcinogen, based on lung cancer findings across a large number of existing occupational studies and positive animal studies. ${ }^{2}$ The National Toxicology Program (NTP) (www.ntp. niehs.nih.gov/ntp/roc/tocl l.html) in the USA followed this by declaring silica a known human carcinogen in 2000. Our own subsequent pooled analysis of 10 large silica exposed cohorts $(65000$ workers, 1000 lung cancer deaths) found a significant positive exposure-response 
trend with cumulative silica exposure, ${ }^{3}$ supporting the IARC decision.

I would argue that the negative results of Brown and Rushton are not that surprising, for two reasons. First, IARC noted in 1997 that positive findings for lung cancer were not consistent across studies, and that specific mineralogic properties of the silica might vary and result in different levels of toxicity. Therefore it is quite possible that a given study might be negative.

Second, the exposure levels in the Brown and Rushton study were rather low. Our pooled exposure-response analysis showed that silica is not a strong lung carcinogen compared to the classic occupational carcinogens such as nickel, arsenic, and asbestos. This is why it took over 20 years of studies to convince IARC and other agencies that silica should be considered a known carcinogen. In our pooled analysis, the lung cancer rate ratios did not increase in categorical analyses until after a cumulative exposure of $2 \mathrm{mg} / \mathrm{m}^{3}$-years (RRs of 1.0, 1. 0, 1.3, 1.5, 1.6 for $<0.4,0.4-2.0$, $2.0-5.4,5.4-12.8$, and $12.8+\mathrm{mg} / \mathrm{m}^{3}$ years). The geometric mean cumulative exposure in Brown and Rushton was $0.31 \mathrm{mg} / \mathrm{m}^{3}$-years, a level which a priori might not be expected to result in detectable excess of lung cancer. The high exposure group in the Brown and Rushton categorical analysis (which showed no lung cancer excess) was $>1.0 \mathrm{mg} / \mathrm{m}^{3}$-year, still a relatively low level (for example, 10 years of working at $0.1 \mathrm{mg} / \mathrm{m}^{3}$, which is the occupational limit in many countries). We do not know the distribution of exposures within the high exposure group, but it may be that there were relatively few highly exposed workers there. The relatively low level of exposure in the Brown and Rushton cohort may be the reason for the fact that only two cases of death from silicosis were observed. It is interesting to note that another cohort of 4600 industrial sand workers in the USA had a similar low overall level of cumulative exposure, but there were 17 deaths from silicosis. ${ }^{4}$ A lung cancer excess was also observed in this cohort, concentrated among those with the highest exposures. Furthermore, a second study of US industrial sand workers, ${ }^{5}$ with some but not complete overlap with Steenland and colleagues, ${ }^{4}$ found an SMR for lung cancer of 1.39 and a significant positive exposure-response trend for cumulative and average exposure.

Figure 1 shows the exposure-response curve for the Brown and Rushton study (UK industrial sand) and the IARC multicentre study (note: I have used the exposure-response data from Brown and Rushton which did not control in the model for quarry, as quarry may be a surrogate for exposure). The figure makes clear that the UK study is restricted to relatively low exposures and that the odds ratios have relatively wide confidence intervals-overall the findings from the UK study are compatible with the IARC study.

There are other aspects of the Brown and Rushton cohort which might tend to result in negative findings for lung cancer. There were only eight lung cancers among those with 20 or more years latency, where an effect might be most anticipated. The overall deficit of lung cancer primarily resulted from a marked deficit at one plant, which also had a significant deficit for all cause mortality and for all cancer mortality, possibly due to that plant having less follow up time and a greater healthy worker effect.

Does this negative finding for the Brown and Rushton cohort mean that there is a threshold below which silica exposure is not dangerous? There are several reasons why this may not be the case. Biologically, it is probably not a good idea to postulate a threshold for carcinogens which act via initiating a mutation in the DNA in a stochastic process. Statistically, it is often difficult to determine the shape of the exposureresponse curve in the low dose reason, even with a large sample size. We looked at this question in our own

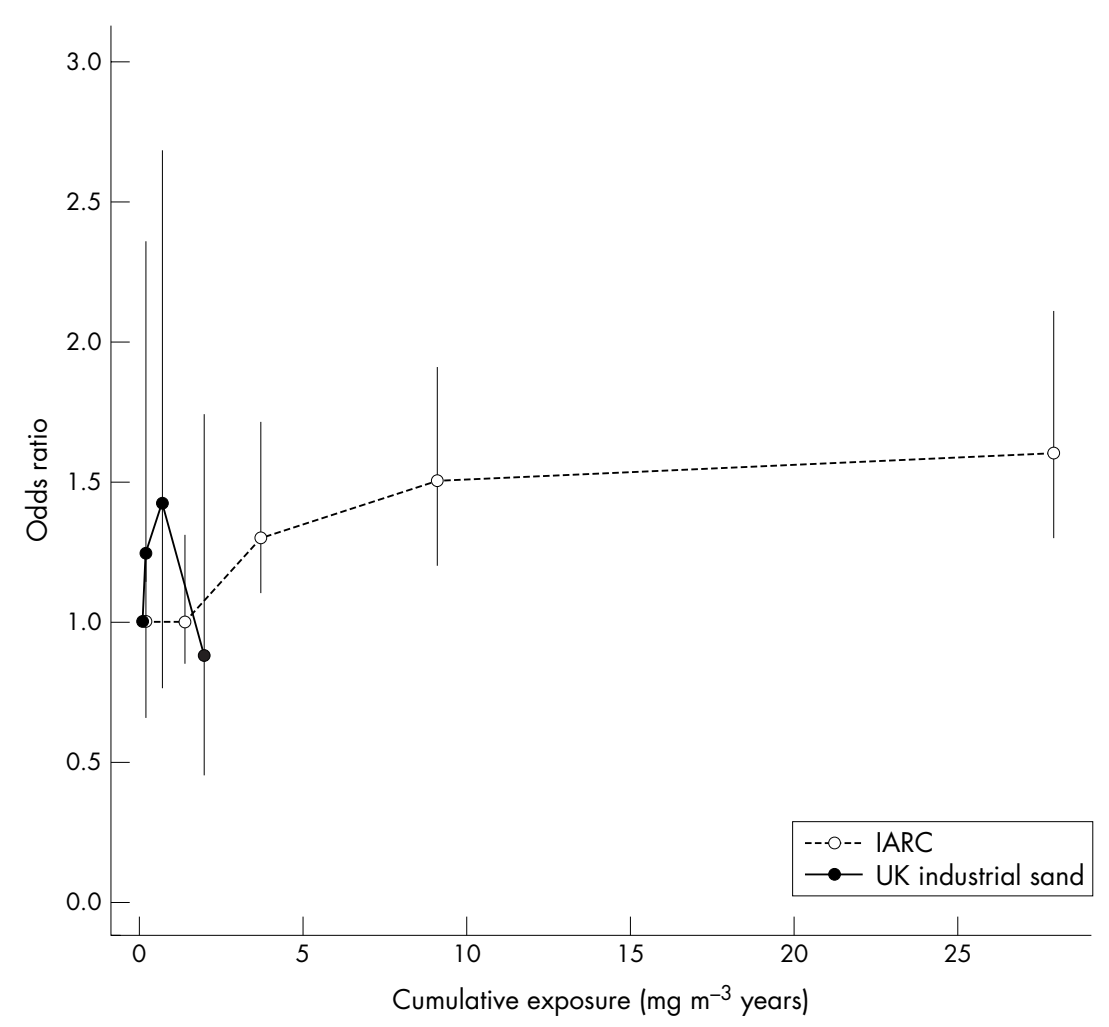

Figure 1 Exposure-response trends for silica and lung cancer in two studies. pooled analysis. ${ }^{6}$ A threshold model provided only modest improvement in the log likelihood over a non-threshold model, and the optimal threshold was low, about $0.33 \mathrm{mg} / \mathrm{m}^{3}$-years. Regulators and policy makers often consider exposure levels for a hypothetical 45 year working lifetime. To stay below a threshold of $0.33 \mathrm{mg} / \mathrm{m}^{3}$-years would require a allowable level of less than $0.01 \mathrm{mg} / \mathrm{m}^{3}$, which is less than a tenth of the current standard in the USA. This very low level is unlikely to be technically feasible in most realistic occupational settings.

My own view is that the current standard in the USA, used in many other countries as well, is clearly too high. Several exposure-response studies in recent years have shown that the current US standard is not sufficiently protective to prevent silicosis. ${ }^{7-10}$ The evidence is strong that silica can cause lung cancer, ${ }^{11}$ and evidence is mounting that silica causes not only silicosis and lung cancer, but also renal disease and autoimmune diseases like arthritis and scleroderma. ${ }^{12}{ }^{13} \mathrm{~A}$ reduction of occupational limits to $0.05 \mathrm{mg} / \mathrm{m}^{3}$ (the NIOSH recommended standard) or to some lower but technically feasible level below $0.05 \mathrm{mg} / \mathrm{m}^{3}$ would go a long way to reducing disease due to occupational exposure. This point has authors. $^{711}$ been made repeatedly by other 
A broader question raised by the findings of Brown and Rushton is how we evaluate consistency in epidemiological studies, and when one might consider that a controversy about a putative carcinogen might be laid to rest. Clearly for silica one should expect that some new studies will be negative for lung cancer, especially when exposure levels are low. Nonetheless, policy makers must judge the weight of the evidence, as has been done by IARC and the NTP, agencies which evaluated more than 30 epidemiological studies of silica exposed workers. Given this level of past research, it might be considered high time for policy makers to act without the perennial call that "more research is needed".

Occup Environ Med 2005;62:430-432. doi: 10.1136/oem.2005.020669
Correspondence to: Dr K Steenland, Rollins School of Public Health, Emory University Atlanta, GA, USA; nsteen|@sph.emory.edu

Competing interests: none declared

\section{REFERENCES}

1 Brown T, Rushton T. Mortality in the US industrial silica sand industry: 2. A retrospective cohort study. Occup Environ Med 2005;62:446-52.

2 IARC. Silica: some silicates, coal dust, and paraaramid fibrils, Monograph 68. Lyon, France: IARC Publications, 1997.

3 Steenland K, Mannetje A, Boffetta P, et al. Pooled exposure-response and risk assessment for lung cancer in 10 cohorts of silica-exposed workers: an IARC multi-centric study. Cancer Causes an IARC multi-centric study.
Control 2001;12:773-84.

4 Steenland K, Sanderson W. Lung cancer among industrial sand workers exposed to crystalline silica. Am J Epidemiol 2001;153:695-703.

5 Hughes JM, Weill H, Rando RJ, et al. Cohort mortality study of North American industrial sand workers. II. Case-referent analysis of lung cancer and silicosis deaths. Ann Occup Hyg 2001;45:201-7.
6 Steenland K, Deddens D. Response to letter from Dr. Ulm. Cancer Causes Control 2002;13:781.

7 Greaves I. Not-so-simple silicosis: a case for public health action. Am J Ind Med 2000;37:245-51.

8 Chen W, Zhuang Z, Attfield $M$, et al. Exposure to silica and silicosis among tin miners in China: exposure-response analyses and risk assessment. Occup Environ Med 2001;58:31-7.

9 Park R, Rice F, Stayner L, et al. Exposure to crystalline silica, silicosis, and lung disease other than cancer in diatomaceous earth industry workers: a quantitative risk assessment. Occup Environ Med 2002;59:36-43.

10 Churchyard G, Ehrlich R, teWater Naude J, et al. Prevalence of silicosis and exposure response associations among goldminers in South Africa. Occup Environ Med 2004;61:811-16.

11 Kriebel D, Rosenberg B. Lung cancer: another good reason to control silica. Cancer Causes Control 2001; 12:785-7.

12 Steenland K, Mannetie A, Attfield M. Pooled analysis of kidney disease mortality and silica exposure in three cohorts. Ann Occup Hyg 2002b;46(suppl 1):10-13.

13 Steenland K, Sanderson W, Calvert G. Kidney disease and arthritis among workers exposed to silica. Epidemiology 2001;12:405-12.

\section{Long term effects of air pollution in Europe}

\section{K Katsouyanni}

\section{Commentary on the paper by Filleul et al (see page 453)}

$\mathrm{T}$ here is an extensive documentation in Europe and North America about the short term effects of air pollution (especially particulate pollution) on health and a general consensus about their order of magnitude. ${ }^{1}$ In contrast, long term effects, which are potentially very important, have been addressed in only a few cohort studies. This is mainly due to the problems of designing and executing large and expensive studies of long duration. Three studies have reported results from the USA, ${ }^{2-4}$ and only one from a Dutch cohort in Europe. $^{5}$ In this issue, results from another European cohort study performed in France are reported. ${ }^{6}$

The long term effects of particulate air pollution reported so far, exceed those of short term exposures and have a larger impact in terms of years of life lost. ${ }^{7-8}$ The effect estimates from cohort studies, especially the ACS study, ${ }^{3}$ have been applied in various health impact assessment (HIA) efforts. ${ }^{9}$ Thus, the fact that there are very few such studies in Europe poses important problems: (1) Can we extrapolate from studies done in the USA, especially when there are known quantitative and qualitative differences between the USA and Europe in the air pollution mix? (2) Are the studies performed so far, enough to get an effect estimate with reasonably general applicability?

The cohort studies reported have used individual data on outcome and confounders, but have generally assessed air pollution in an "ecological" waythat is, using one fixed monitor per city and assuming all residents of this city to be exposed to the same amount of pollution. In the Dutch study, ${ }^{5}$ an effort was made to refine the measurement by adding information on individual residential characteristics (that is, proximity to a major road). The results from these studies are generally consistent, and the fact that all major confounders have been assessed individually leaves little doubt that the reported associations are not due to hidden confounders.

In the study by Filleul et al, 24 areas from seven cities are investigated. In all areas a fixed site monitoring station had been established, and persons with residences within a distance from the monitor have been included. Each subject has been assigned an exposure level corresponding to the relevant monitoring site. Assigning different exposures within the same city according to residence, adds an additional component of exposure misclassification due to the fact that subjects may move around a town and have an exposure closer to the average of all monitors. The authors then excluded the subjects whose exposure was assessed by monitors influenced by local traffic. The assumption was that this exposure may be an overestimate of the population exposure and lead to a biased effect estimate. By excluding these six areas, they excluded the whole city of Toulouse, the highest pollution area of Bordeaux, and the two highest of Marseille. Their argument for excluding these areas is plausible, but highlights the misclassification problems inherent in such assessments and the need to link to real population timeactivity survey data (which are usually not available).

It is only after excluding these six areas that an effect of particulate and traffic related pollutants is detected. I think that an analysis at the city level, using as exposure metric the average of all city monitors would provide a useful sensitivity analysis for comparison purposes with previously reported results from other cohort studies.

It should be noted that the above exclusion of monitors influenced directly by traffic should be interpreted as exclusion of measurements hypothesised as being unrepresentative of the population exposure, as the authors correctly point out. It does not mean that traffic pollution is not an important (or indeed the most important) component of exposure to air pollution. The results of the present study reinforce the role 
of traffic pollution on human health effects, since the pollutants identified (black smoke and $\mathrm{NO}_{2}$ ) as responsible are indicators of traffic pollution. This result is consistent with other results reported in the literature. ${ }^{5} 10$

The fact that cohort studies assessing long term health effects of air pollution are sparse in Europe and concern specific populations is a problem hindering the attempts to completely evaluate the public health consequences of this exposure. Additionally, there are difficulties concerning exposure assessment with respect to the metrics used, the time period of measurement, and the unknown size of misclassification. The two studies published so far used existing cohort data and managed to provide very useful information with relatively limited resources. However, these studies have obvious limitations as they were initially designed for other purposes. Furthermore, the important differences in air pollution between the USA and Europe cast doubts on the use of estimates from US cohorts for HIA in European populations.

Therefore, a well planned, multicentre cohort study designed to assess air pollution effects is now timely and should be considered a research priority.

Occup Environ Med 2005;62:432-433.

doi: 10.1136/oem.2004.019166

Correspondence to: Associate Prof.

K Katsouyanni, Department of Hygiene and

Epidemiology, University of Athens Medical

School, 75 Mikras Asias Street, 11527 Athens,

Greece; kkatsouy@med.voa.gr

Competing interests: none declared

\section{REFERENCES}

1 WHO. Health aspects of air pollution with particulate matter, ozone and nitrogen dioxide. Report on a WHO working group, Document EUR/03/5042688. Copenhagen: WHO Regional Office for Europe, 2003.

2 Dockery DW, Pope III CA, Xu X, et al. An association between air pollution and mortality in six US cities. N Engl J Med 1993;329:1753-9.

3 Abbey DE, Nishino N, McDonnell WF, et al. Long-term inhalable particles and other air pollutants related to mortality in nonsmokers. Am J Respir Crit Care Med 1999;159:373-82.
4 Pope CA, Burnett RT, Thun MJ, et al. Lung cancer, cardiopulmonary mortality, and long-term exposure to fine particulate air pollution. JAMA 2002;287:1132-41.

5 Hoek G, Brunekreef B, Goldbohm S, et al. Association between mortality and indicators of traffic-related air pollution in the Netherlands: a cohort study. Lancet 2002:360:1203-9.

6 L Filleul, V Rondeau, S Vandentorren, et al. Twenty five year mortality and air pollution: results from the French PAARC survey: the influence of the assessment of exposure. Occup Environ Med 2005;62:453-60.

7 Kunzli N, Kaiser R, Medina S, et al. Public health impact of outdoor and traffic related air pollution: a European assessment. Lancet 2000;356:795-801.

8 Brunekreef B. Air pollution and life expectancy: is there a relation? Occup Environ Med 1997;54:781-4.

9 Cohen A, Anderson HR, Ostro B, et al. Mortality impacts of urban air pollution. In: Ezzati $M$, Lopez AD, Rodgers A, Murray CJL, eds. Comparative quantification of health risks: global and regional burden of disease attributable to selected major risk factors. Geneva: World Health Organisation, 2004.

10 Katsouyanni K, Touloumi G, Samoli E, et al. Confounding and effect modification in the short term effects of ambient particles on total mortality: results from 29 European cities within the APHEA2 project. Epidemiology 2001;12:521-31. 